\title{
In vivo treatment with epigenetic modulating agents induces transcriptional alterations associated with prognosis and immunomodulation in multiple myeloma
}

\author{
Ken Maes ${ }^{1}$, Eva De Smedt ${ }^{1}$, Alboukadel Kassambara2,3, Dirk Hose ${ }^{4}$, Anja Seckinger ${ }^{4}$, \\ Els Van Valckenborgh ${ }^{1}$, Eline Menu ${ }^{1}$, Bernard Klein ${ }^{2,3,5}$, Karin Vanderkerken ${ }^{1}$, \\ Jérôme Moreaux ${ }^{2,3,5, *}$ and Elke De Bruyne ${ }^{1, *}$ \\ ${ }^{1}$ Department of Hematology and Immunology, Myeloma Center Brussels, Vrije Universiteit Brussel, Brussels \\ 2 Department of Biological Haematology, CHU Montpellier, Montpellier, France \\ ${ }^{3}$ Institute of Human Genetics, CNRS-UPR1142, Montpellier F-34396, France \\ ${ }^{4}$ Medizinische Klinik, Universitätsklinikum Heidelberg, Heidelberg, Germany \\ ${ }^{5}$ University of Montpellier 1, UFR de Médecine, Montpellier, France \\ * These authors contributed equally to this work \\ Correspondence to: Elke De Bruyne, email: eldebruy@vub.ac.be \\ Keywords: Epigenetics, Multiple Myeloma, HDACi, DNMTi, murine model \\ Received: October 13,2014 Accepted: December 17,2014 Published: December 26, 2014
}

This is an open-access article distributed under the terms of the Creative Commons Attribution License, which permits unrestricted use, distribution, and reproduction in any medium, provided the original author and source are credited.

\section{ABSTRACT}

Histone deacetylase inhibitors (HDACi) and DNA methyltransferase inhibitors (DNMTi) are in early clinical development for multiple myeloma (MM) therapy. Despite all encouraging pre-clinical data, clinical activity of HDACi and DNMTi is mostly lacking. To optimize the trials, characterization of the in vivo response towards HDACi and DNMTi will be crucial. Therefore, we investigated the transcriptional response after in vivo treatment with the HDACi quisinostat or DNMTi decitabine using the murine 5T33MM model.

We identified 504 and 154 genes deregulated by quisinostat and decitabine, respectively. Of interest, MM patients' gene expression levels of 62 quisinostat- and 25 decitabine-deregulated genes were predictive for overall survival of patients. This prognostic information was implemented in a DNA methylation and histone acetylation score. A high score was related to a high proliferative and immature phenotype of MM cells. Furthermore, highly scored MM patients had an adverse overall survival. Interestingly, bio-informatic prediction tools revealed an association of quisinostat-deregulated genes with lymphocyte activation, proliferation, immuneeffector mechanisms and T-helper-1 development.

Overall, treatment of 5T33 MM mice with epigenetic modulating agents led to the translation of gene signatures to predict overall survival of MM patients. HDACi mainly deregulated tumoral immunomodulatory pathways, supporting the rationale to combine HDACi with immunomodulatory therapies.

\section{INTRODUCTION}

Multiple myeloma (MM) is a hematological plasma cell malignancy. Malignant plasma cells mainly reside in the bone marrow (BM) where numerous interactions between MM cells and the BM compartments confer survival and growth of MM cells and induce angiogenesis, bone destruction, drug resistance and immune escape [1]. MM is characterized by a genetic heterogeneity that is translated to a large range of patients' survival times [2]. Prognosis of MM patients can be assessed by the International Staging System reflecting disease activity and inflammatory status. The molecular characteristics of MM cells are determined by chromosomal alterations and alterations in gene expression [3-11]. Treatments 
consist of combinations of various drug classes such as glucocorticoids, proteasome inhibitors, alkylators and immunomodulatory drugs (IMiDs) with or without high dose melphalan (HDM) and autologous stem cell transplantation (ASCT) [12]. Although the combination of these drugs have significantly improved patient survival [13-15], a majority of patients still relapses, emphasizing the need to find alternative treatment options.

Epigenetic aberrations have been reported to contribute to $\mathrm{MM}$ pathogenesis, together with genetic abnormalities [16-18]. DNA methylation and posttranslational histone modification are two major epigenetic modifications. DNA methylation is considered a prognostic marker in human MM [19-23] and differences can be detected between MGUS and MM in terms of gene-specific methylation and global hypomethylation of non- $\mathrm{CpG}$ islands (repetitive elements or intergenic regions) $[22,24]$. Moreover, cytogenetic MM subgroups are defined by differences in DNA methylation patterns $[22,25]$. Among posttranslational histone modifications, methylation and acetylation are extensively studied in relation to cancer [26]. The $\mathrm{t}(4 ; 14)$ translocation in $\mathrm{MM}$ cells, present in approximately $15 \%$ of the patients, leads to overexpression of WHSC1 encoding for the histone methyltransferase MMSET [27]. In addition, mutations in the histone methyltransferases WHSC1L1, MLL1-3 and in the histone demethylase UTX are identified in MM patients [28, 29].

Epigenetic modulating agents such as histone deacetylase inhibitors (HDACi) and DNA methyltransferase inhibitors (DNMTi) interfere with epigenetic aberrations in cancer [30]. HDACi used alone or in combination with conventional anti-MM agents have potent pre-clinical anti-MM effects [31-33]. The same holds true for the DNMTi azacytidine or decitabine [34, 35]. Furthermore, using HDACi and DNMTi, we recently identified gene expression-based risk scores, which are predictive for the sensitivity of MM cells towards DNMTi and HDACi as well as for the overall survival of MM patients. This pre-clinical work provides the rationale for clinical trials evaluating the anti-MM activity of HDACi. While single-agents HDACi appeared to mediate little to no clinical activity [36-38], combinatory treatment of the pan-HDACi vorinostat or panobinostat in combination with respectively the proteasome inhibitor bortezomib or bortezomib plus dexamethasone did prolong progression free survival with respectively 0.8 months and 3.9 months $[39,40]$. However, the clinical relevance in terms of overall survival is not yet clear and a high occurrence of side effects was observed $[39,40]$. In addition, a phase II trial of the combination of panobinostat with melphalan, thalidomide and prednisone was also associated with a high occurrence of side effects [41]. As for the DNMTi, the therapeutic potential in MM is yet to be evaluated in clinical trials.

These above mentioned clinical trials raise questions about the efficacy of epigenetic modulating agents in MM patients. Although the pre-clinical studies on epigenetic modulating agents demonstrated pleiotropic mechanisms of action explaining their anti-MM activity [34, 42-44], it is widely known that the drug response of MM cells is influenced by interactions with the BM microenvironment and immune system [45-47]. Thus, a better understanding of the in vivo mechanisms of epigenetic modulating agents will be crucial as it can provide new possibilities for combinatory therapies, identify more specific targets, reduce side effects and identify the patients whom might benefit from treatment with epigenetic modulating agents [48]. We have previously demonstrated potent in vivo antiMM activity for decitabine and the HDACi quisinostat using the immune competent, syngeneic 5TMM models $[31,32,34]$. These models are suitable for studies on MM biology and pre-clinical drug testing because they take into account the BM microenvironment and immune system [32, 49-52]. Here, we investigated the in vivo transcriptional response of MM cells towards decitabine and quisinostat in the 5T33MM model to validate our previous work on the prognostic relevance and to identify new in vivo relevant targets.

\section{RESULTS}

\section{In vivo treatment with epigenetic modulating agents induced transcriptional changes linked with survival of MM patients}

The syngeneic immunocompetent 5T33MM model was used to study the in vivo transcriptional response towards the DNMTi decitabine and the HDACi quisinostat. Quisinostat is a hydroxamate-based panHDAC inhibitor with similar HDAC selectivity as panobinostat [53]. In a preliminary series of experiments, the sub-lethal concentrations showing minimal effects on BM plasmacytosis ensuring the yield of good quality RNA were determined (data not shown). Next, mice with established disease were treated with these sub-lethal concentrations of decitabine or quisinostat for 5 days (Supplementary Figure S1A). Total BM plasmacytosis was above $80 \%$ in the vehicle and decitabine-treated mice, while quisinostat decreased tumor load to approximately $60 \%$ (Supplementary Figure S1B). Overall, the shortterm treatment had only minimal anti-MM effects thus warranting good sample quality.

Using Significance Analysis of Microarray (SAM), decitabine treatment resulted in a significant upregulation of 172 probe sets and downregulation of 8 ones (false discovery rate $(\mathrm{FDR}) \leq 5 \%$; ratio $\geq 2$ ), corresponding to 154 unique genes. Quisinostat treatment induced a significant upregulation of 569 probe sets and downregulation of 5 probe sets (FDR $\leq 5 \%$; ratio $\geq 2$ ), 
Table 1: Prognostic value of the deregulated genes as determined by Maxstat analysis. The human orthologs of the in vivo deregulated murine genes after treatment with quisinostat or decitabine were used to determine the prognostic value in the HM training cohort.

\begin{tabular}{|c|c|c|c|}
\hline \multicolumn{4}{|c|}{ Decitabine } \\
\hline Probeset & Name & $\begin{array}{l}\text { Benjamini-Hochberg } \\
\text { adjusted p-value (FDR) }\end{array}$ & Hazard ratio \\
\hline \multicolumn{4}{|c|}{ Good prognostic genes (5) } \\
\hline 203708_at & PDE4B & 0.016 & 0.184 \\
\hline 225629_s_at & ZBTB4 & 0.051 & 0.346 \\
\hline 217492_s_at & PTENP1 & 0.049 & 0.358 \\
\hline 202917_s_at & S100A8 & 0.034 & 0.363 \\
\hline 215210_s_at & DLST & 0.049 & 0.405 \\
\hline \multicolumn{4}{|c|}{ Bad prognostic genes (20) } \\
\hline 219684_at & RTP4 & 0.046 & 5.158 \\
\hline 224701_at & PARP14 & 0.002 & 4.106 \\
\hline 217503_at & STK17B & 0.010 & 3.796 \\
\hline 222848_at & CENPK & 0.007 & 3.743 \\
\hline 223271_s_at & CTDSPL2 & 0.007 & 3.681 \\
\hline 228351_at & HEATR1 & 0.046 & 3.633 \\
\hline 204709_s_at & KIF23 & 0.012 & 3.550 \\
\hline 213647_at & DNA2 & 0.009 & 3.537 \\
\hline 219211_at & USP18 & 0.020 & 3.140 \\
\hline 212416_at & SCAMP1 & 0.048 & 2.981 \\
\hline 212577_at & SMCHD1 & 0.024 & 2.782 \\
\hline 208901_s_at & TOP1 & 0.026 & 2.753 \\
\hline 224227_s_at & BDP1 & 0.041 & 2.711 \\
\hline 242625_at & RSAD2 & 0.049 & 2.701 \\
\hline 213742_at & SRSF11 & 0.036 & 2.611 \\
\hline 218585_s_at & DTL & 0.036 & 2.582 \\
\hline 228006_at & PTEN & 0.045 & 2.580 \\
\hline 225647_s_at & CTSC & 0.045 & 2.554 \\
\hline 243213_at & STAT3 & 0.046 & 2.538 \\
\hline 226942_at & PHF20L1 & 0.047 & 2.382 \\
\hline \multicolumn{4}{|c|}{ Quisinostat } \\
\hline Probeset & Name & $\begin{array}{c}\text { Benjamini-Hochberg } \\
\text { p-value (FDR) }\end{array}$ & Hazard ratio \\
\hline \multicolumn{4}{|c|}{ Good prognostic genes (31) } \\
\hline 223806_s_at & NAPSA & 0.048 & 0.153 \\
\hline 222717_at & SDPR & 0.045 & 0.184 \\
\hline 203708_at & PDE4B & 0.029 & 0.184 \\
\hline 210889_s_at & FCGR2B & 0.008 & 0.237 \\
\hline 224826_at & GPCPD1 & 0.009 & 0.240 \\
\hline 202878_s_at & CD93 & 0.012 & 0.261 \\
\hline 201445_at & $\mathrm{CNN} 3$ & 0.007 & 0.270 \\
\hline 200934_at & DEK & 0.020 & 0.281 \\
\hline 212298_at & NRP1 & 0.013 & 0.302 \\
\hline
\end{tabular}




\begin{tabular}{|c|c|c|c|}
\hline 201243_s_at & ATP1B1 & 0.044 & 0.314 \\
\hline 224586_x_at & SUB1 & 0.046 & 0.322 \\
\hline 210664_s_at & TFPI & 0.018 & 0.326 \\
\hline 235593_at & ZEB2 & 0.050 & 0.342 \\
\hline 207794_at & $\mathrm{CCR} 2$ & 0.046 & 0.347 \\
\hline 225175_s_at & SLC44A2 & 0.039 & 0.349 \\
\hline 224964_s_at & GNG2 & 0.045 & 0.353 \\
\hline 203799_at & $\begin{array}{c}\text { CD302 I// LY75- } \\
\text { CD302 }\end{array}$ & 0.045 & 0.355 \\
\hline 224983_at & SCARB2 & 0.043 & 0.358 \\
\hline 212268_at & SERPINB1 & 0.044 & 0.359 \\
\hline 222391_at & TMEM30A & 0.036 & 0.360 \\
\hline 209916_at & DHTKD1 & 0.039 & 0.363 \\
\hline 202917_s_at & S100A8 & 0.048 & 0.363 \\
\hline 209829_at & FAM65B & 0.039 & 0.367 \\
\hline 200965_s_at & ABLIM1 & 0.044 & 0.374 \\
\hline 226841_at & MPEG1 & 0.050 & 0.375 \\
\hline 219062_s_at & ZCCHC2 & 0.045 & 0.382 \\
\hline 224442_at & PHF6 & 0.044 & 0.388 \\
\hline 202990_at & PYGL & 0.049 & 0.390 \\
\hline 205790_at & SKAP1 & 0.045 & 0.402 \\
\hline 215210_s_at & DLST & 0.049 & 0.405 \\
\hline 226925_at & ACPL2 & 0.049 & 0.409 \\
\hline \multicolumn{4}{|c|}{ Bad prognostic genes (30) } \\
\hline 204040_at & RNF144A & 0.043 & 5.358 \\
\hline 217503_at & STK17B & 0.017 & 3.796 \\
\hline 223271_s_at & CTDSPL2 & 0.010 & 3.681 \\
\hline 203091_at & FUBP1 & 0.049 & 3.336 \\
\hline 241879_at & LPP & 0.044 & 3.195 \\
\hline 203449_s_at & TERF1 & 0.047 & 3.195 \\
\hline 215111_s_at & TSC22D1 & 0.040 & 3.133 \\
\hline 212151_at & PBX1 & 0.043 & 3.078 \\
\hline 203636_at & MID1 & 0.020 & 3.046 \\
\hline 201912_s_at & GSPT1 & 0.038 & 2.985 \\
\hline 212416_at & SCAMP1 & 0.049 & 2.981 \\
\hline 209798_at & NPAT & 0.044 & 2.944 \\
\hline 233011_at & ANXA1 & 0.043 & 2.944 \\
\hline 222133_s_at & PHF20L1 & 0.038 & 2.860 \\
\hline 204809_at & CLPX & 0.035 & 2.860 \\
\hline 223319_at & GPHN & 0.037 & 2.789 \\
\hline 212577_at & SMCHD1 & 0.036 & 2.782 \\
\hline 208901_s_at & TOP1 & 0.038 & 2.753 \\
\hline 224227_s_at & BDP1 & 0.045 & 2.711 \\
\hline 1557737_s_at & NKTR & 0.050 & 2.651 \\
\hline
\end{tabular}




\begin{tabular}{|c|c|c|c|}
\hline 208831_x_at & SUPT6H & 0.050 & 2.640 \\
\hline 224848_at & CDK6 & 0.047 & 2.625 \\
\hline 213742_at & SRSF11 & 0.048 & 2.611 \\
\hline 218585_s_at & DTL & 0.043 & 2.582 \\
\hline 214953_s_at & APP & 0.046 & 2.581 \\
\hline 228006_at & PTEN & 0.046 & 2.580 \\
\hline 225647_s_at & CTSC & 0.049 & 2.554 \\
\hline 220994_saat & STXBP6 & 0.045 & 2.546 \\
\hline 225097_at & HIPK2 & 0.043 & 2.539 \\
\hline 202446_s_at & PLSCR1 & 0.049 & 2.447 \\
\hline
\end{tabular}

corresponding to 504 unique genes. Ninety-eight genes were commonly deregulated by decitabine and quisinostat (Figure 1, Supplementary Tables S1-S2). The prognostic value of the human orthologs for the overall survival of patients with MM of murine deregulated genes was investigated using patients data from the University
Clinics of Heidelberg and Montpellier (HM)-cohort as a training cohort and the University of Arkansas for Medical Sciences-Total Therapy 2 (TT2-cohort) as validation cohort [54-57]. Using the HM-cohort, five decitabine-deregulated probe sets had a prognostic value for a better overall survival and 20 for an adverse one
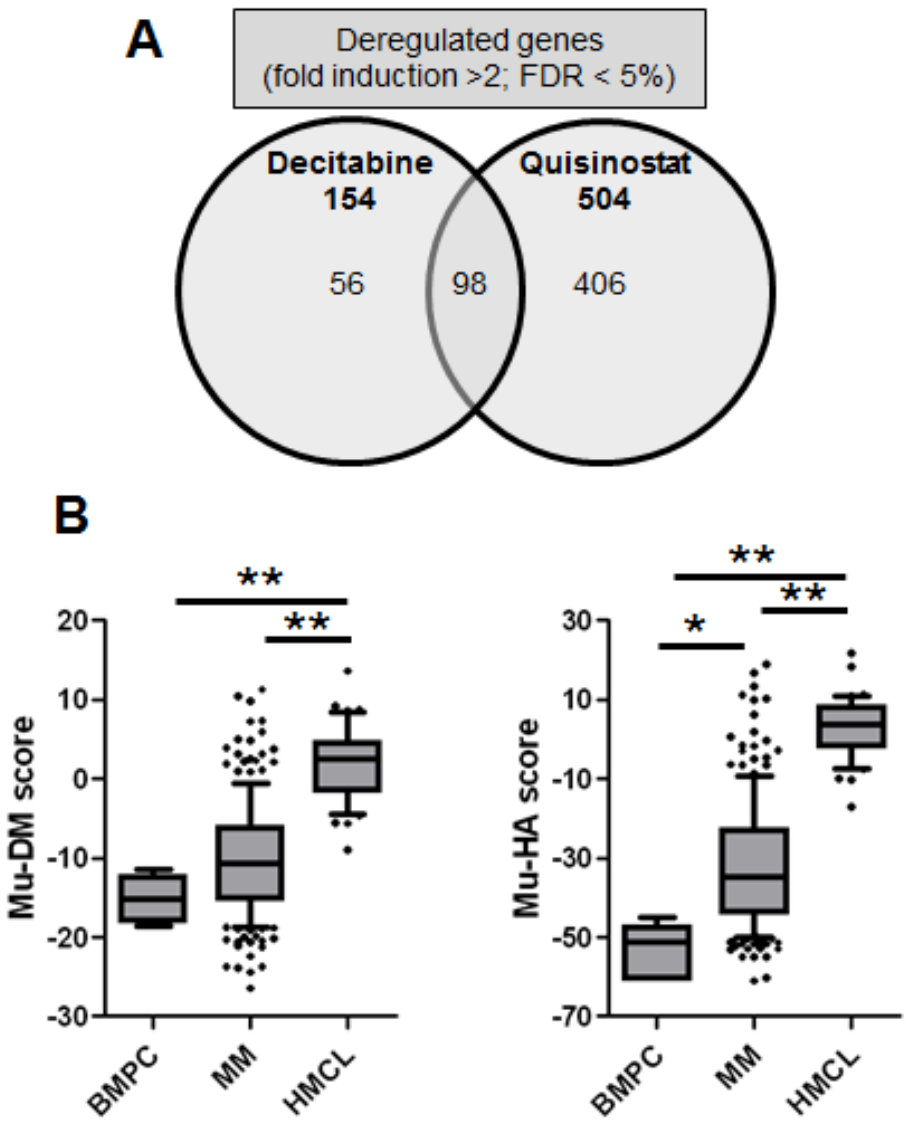

Figure 1: Overview of the in vivo transcriptional response towards decitabine or quisinostat and the gene expressionbased risk scores. A: Venn-diagram of deregulated genes after in vivo treatment of the 5T33MM model with decitabine or quisinostat. Microarray data were normalized using MAS5 and analyzed using SAM for the identification of differentially expressed probe sets (ratio $\geq 2$, Benjamini-Hochberg $\mathrm{p}$ value $<0.05$ ). B: The Mu-DM and Mu-HA score during MM progression. The prognostic value of decitabineor quisinostat-deregulated genes was calculated using Maxstat. Decitabine and quisinostat led to deregulation of respectively 25 and 61 prognostic genes which were used to develop a gene expression-based risk score as explained in Material and Methods. The boxes represent median and 10-90 percentiles of the score values during MM progression. $*=p<0.05, * * p<0.001$. BMPC $=$ healthy donor bone marrow plasma cell, $\mathrm{MM}=$ multiple myeloma, $\mathrm{HMCL}=$ human myeloma cell lines. 
(Table 1). Thirty-one quisinostat-deregulated genes had a favourable prognostic value and 30 an adverse one (Table $1)$. The prognostic information of the 25 decitabine- or 61 quisinostat-deregulated genes was implemented into respectively a murine DNA methylation (Mu-DM) score or a murine histone acetylation (Mu-HA) score, as described in Material and Methods. Subsequently, we analyzed the scores during MM progression [58]. MM cells had a higher Mu-HA score $(\mathrm{p}<0.05)$ compared to purified healthy plasma cells (BMPCs). HMCLs had significant higher scores $(p<0.0001)$ compared to MM cells and BMPCs (Figure 1). Both scores could predict patients' overall survival. In the training cohort, a maximum difference in overall survival (OS) was identified with a Mu-DM score of -6.06 (Figure 2A). Patients with Mu-DM score $\leq-6.06$ had a significant lower risk $(80 \%$ of the patients who did not reach median OS) compared to patients with a Mu-DM score $>-6.06$ ( $20 \%$ of the patients with a median OS of 25 months). For the Mu-HA score, a maximal difference in OS was observed with -20.13 as cut-off, splitting patients in a lowrisk group (Mu-HA score $\leq-20.13 ; 77.7 \%$ of the patients who did not reach median OS) and a high-risk group (MuHA score $>-20.13 ; 22.3 \%$ of the patients with a median survival of 24 months) (Figure 2A). This prognostic value of the score was validated in an independent validation cohort (TT2-cohort) as shown in Figure 2B. We then evaluated whether the scores could have a prognostic value in relapsed patients. Using the Mulligan-cohort, including patients treated with bortezomib after relapse, only the Mu-HA score kept prognostic value (Figure 2C). Next, we evaluated whether the scores could be used to predict response to therapy. Using the HM-cohort, we could not find a significant difference in the distributions of low scored and high scored patients between different response groups following high-dose therapy and autologous stem cell transplantation (data not shown). For the Mulligan-cohort we only tested the Mu-HA score. The distributions of low scored and high scored patients were significantly different between non-responders (no change + progressive disease) compared to responders (complete response + partial response + minimal response) (Supplementary Table S3). The prediction had a high specificity $(97.3 \%)$, but a low sensitivity (16.1\%).

Next, the prognostic value for overall survival of $\mathrm{Mu}-\mathrm{DM}$ and $\mathrm{Mu}-\mathrm{HA}$ scores was compared with conventional prognostic factors including beta-2microglobulin (B2m), International Staging (ISS), $\mathrm{t}(4 ; 14)$ and del17p. We also included other gene expression-based risk scores such as High Risk Score (HRS corresponding to UAMS-70-gene model) [8], Intergroupe Francophone du Myélome (IFM) score [4], Risk Score (RS) [7], DNA methylation (DM) score [35], histone acetylation (HA) score [59] and gene expression-based proliferation
A

HM training cohort $(\mathrm{N}=206)$
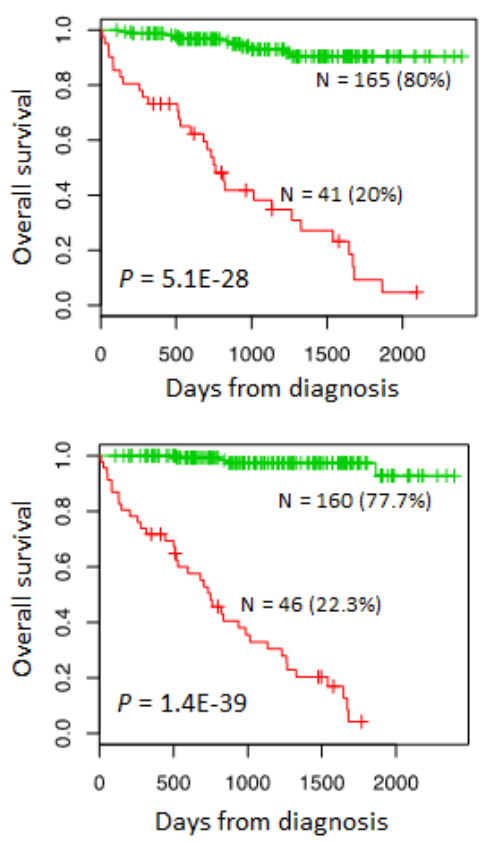

B
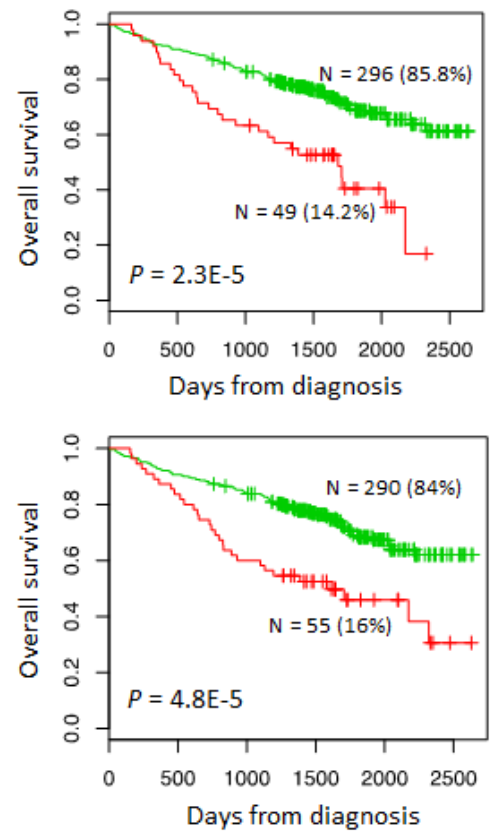

C

Mulligan cohort $(\mathrm{N}=152)$
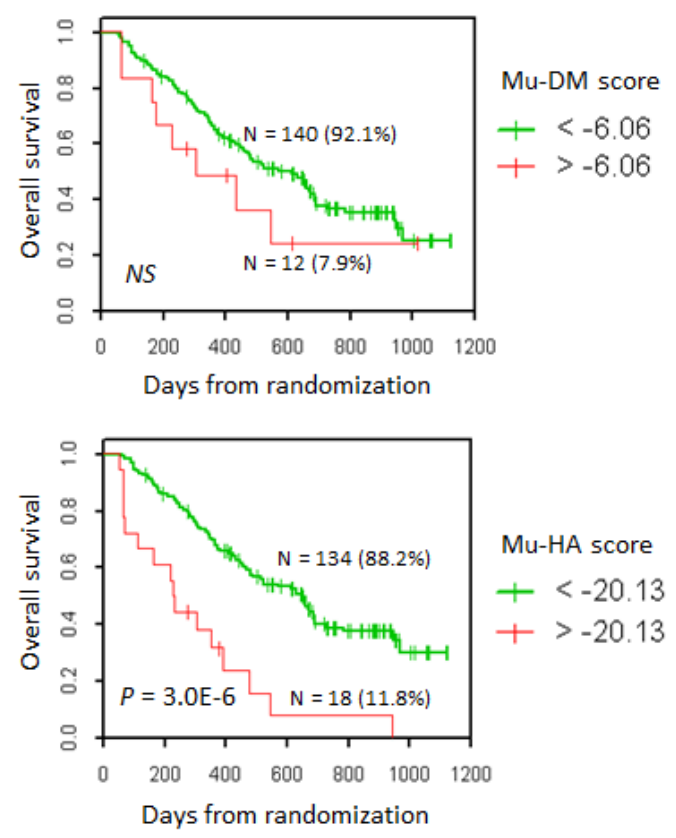

Figure 2: The prognostic value of the Mu-DM and Mu-HA score in terms of overall survival. A: Using Maxstat analysis, the prognostic value of Mu-DM (top) and Mu-HA (bottom) score was calculated by the optimal separation of patients of the HM-cohort $(n=206)$ in a low and high risk group based on a cut-off value (-6.06 for Mu-DM score; -20.13 for Mu-HA score). B: The prognostic value of the Mu-DM (top) and Mu-HA (bottom) score were tested in the independent TT2-cohort ( $\mathrm{n}=345)$ using the same cut-off value as obtained in the HM-cohort. C: The prognostic value of the Mu-DM (top) and Mu-HA (bottom) score were tested in the independent Mulligan-cohort using the same cut-off value as obtained in the HM-cohort. 
index (GPI) [5]. Univariate Cox analysis showed that all these factors have prognostic value (Supplementary table S4) [5, 35, 59]. When analyzed 2 by 2, Mu-DM remained significant with del17p and Mu-HA score in the HM training cohort. The Mu-HA score remained significant with $\mathrm{t}(4 ; 14)$ and $\mathrm{Mu}-\mathrm{DM}$ in bivariate analyses. Multivariate Cox analysis with all parameters tested together showed that $\mathrm{Mu}-\mathrm{DM}, \mathrm{Mu}-\mathrm{HA}$ and $\mathrm{t}(4 ; 14)$ remained independent prognostic factors in the HM training cohort. In the TT2 validation cohort, Cox bivariate analysis showed significance of $\mathrm{Mu}-\mathrm{DM}$ and $\mathrm{Mu}-\mathrm{HA}$ score together with all factors including the previously reported DM and HA scores but not with HRS and IFM scores
(Supplementary table S4). HRS and $t(4 ; 14)$ remained independent prognostic factors when all parameters were tested together in the TT2 validation cohort. When tested with the previously reported DM and HA score, the Mu$\mathrm{DM}$ and Mu-HA score remained independent in the HM validation cohort but not in the TT2 training cohort in the multivariate analysis (Supplementary Table S4).

To investigate the characteristics of the stratified patients, the distribution of the $\mathrm{Mu}-\mathrm{DM}$ and the Mu-HA score among the 8 molecular subgroups of MM using the TT2-cohort was analyzed [60]. Both scores were significantly higher $(\mathrm{p}<0.05)$ in the proliferation subgroup (PR) compared to all other subgroups (Figure 3A). The PR
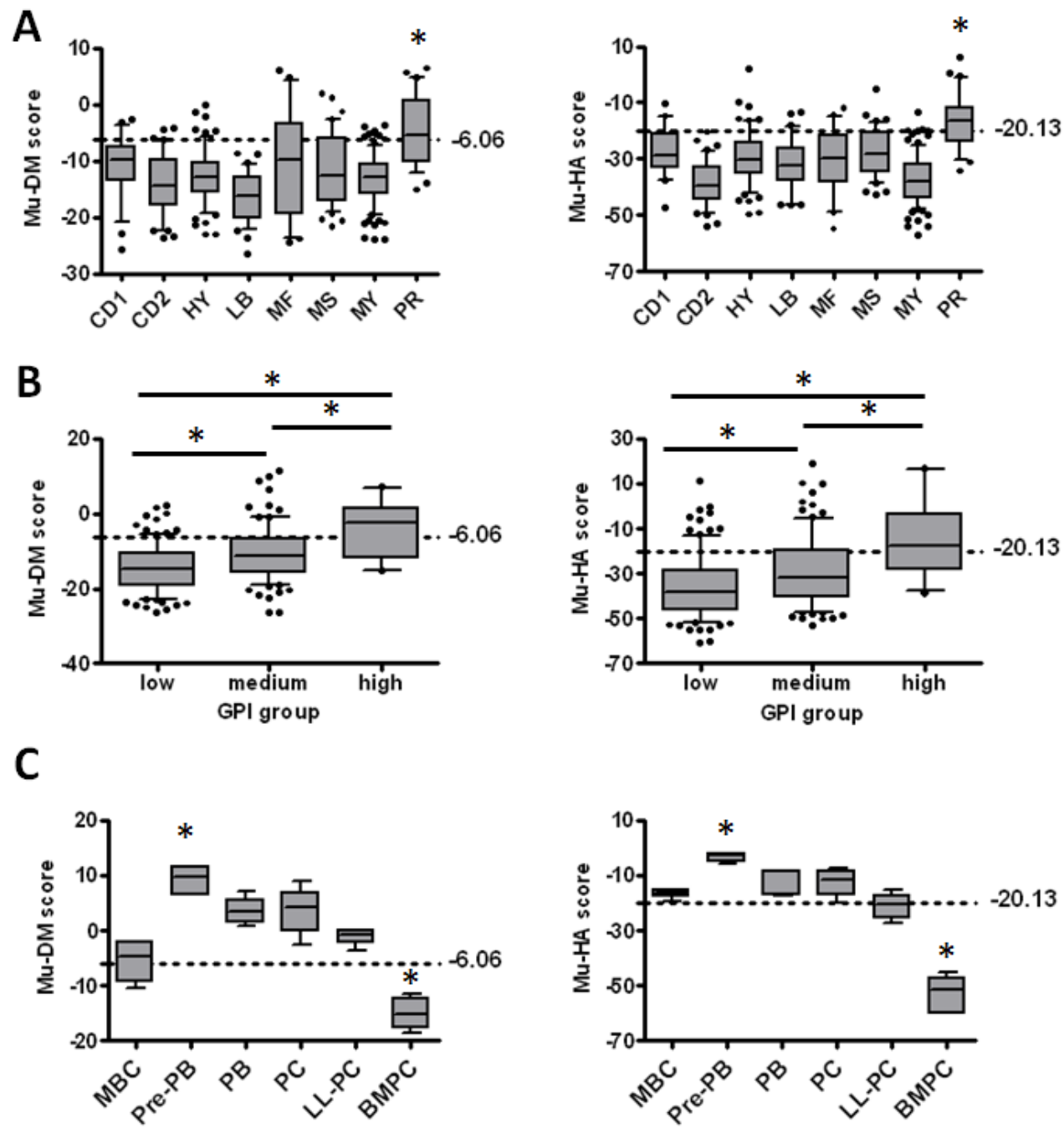

Figure 3: The score values in the different MM molecular subgroups, gene expression-based proliferation index (GPI) subgroups and during B-cell development. A: The Mu-DM (left) and Mu-HA (right) score values were calculated based on the gene expression data of the $8 \mathrm{MM}$ molecular subgroups of the TT2-cohort. $\mathrm{PR}=$ proliferation, $\mathrm{LB}=$ low bone disease, $\mathrm{MS}=\mathrm{MMSET}$, HY $=$ hyperdiploid, CD1 = cyclin D1, CD2 = cyclin D2, MF = MAF; MY = myeloid. * indicates higher score value compared to all other groups with $\mathrm{p}<0.05$. B: The Mu-DM (left) and Mu-HA (right) score values were calculated in the different gene expression-based proliferation index groups $(\mathrm{GPI}){ }^{*}=\mathrm{p}<0.05$. C: The score values in the different stages of in vitro generated plasma cell differentiation. $\mathrm{MBC}=$ memory $\mathrm{B}$-cell, $\mathrm{PPB}=$ pre-plasmablast, $\mathrm{PB}=$ plasmablast, $\mathrm{PC}=$ early plasma cell, LL-PC = long-lived plasma cell, $\mathrm{BMPC}=$ healthy donor bone marrow plasma cell. * indicates $\mathrm{p}<0.05$ compared to all other groups. The boxes represent median and 10-90 percentiles of the score values. Dots are outliers and the dotted lines represent the cut-off value for each score. 
subgroup was the only group with a median score above the cut-point and has been associated with a poor prognosis [60]. In addition, a significant correlation between GPI groups from $\mathrm{HM}$-cohort and $\mathrm{Mu}-\mathrm{DM}$ or $\mathrm{Mu}-\mathrm{HA}$ score was identified $(\mathrm{r}=0.36 ; \mathrm{p}<.01 ; \mathrm{n}=206$ and $\mathrm{r}=0.32 ; \mathrm{p}<$ $.01 ; n=206$ respectively) in MM cells of patients. This is further confirmed by the significant gradual increase in the $\mathrm{Mu}-\mathrm{DM}$ and $\mathrm{Mu}-\mathrm{HA}$ scores from $\mathrm{GPI}^{\text {low }}$ to GPI ${ }^{\text {medium }}$ and GPI ${ }^{\text {high }}$ groups $(\mathrm{p}<0.05)$ (Figure 3B) [5]. Recently, the presence of a hierarchical plasma cell progenitor organization was described in the BM of MM patients and it was furthermore suggested that an epigeneticmediated plasticity exists between these plasma cell progenitors [61]. Therefore, we analyzed the scores in the in vitro generated transitional stages from memory B-cell to plasma cells $[58,62]$. We found that both scores were significantly higher $(\mathrm{p}<0.05)$ in pre-plasmablast $($ Pre-PB) stages and significantly lower $(\mathrm{p}<0.05)$ in healthy donor BMPCs compared to all other conditions. The other stages were considered as having an intermediate $\mathrm{Mu}-\mathrm{DM}$ and Mu-HA score with plasmablasts (PBs), plasma cells (PCs) and long-lived plasma cells (LL-PCs) having a higher $\mathrm{Mu}-$
DM score compared to memory B-cells (MBCs) (Figure 3C). In summary, quisinostat and decitabine altered in vivo the expression of a gene signature that is associated with prognosis allowing risk stratification of patients. High scores are furthermore linked with a proliferative and immature plasma cell phenotype.

\section{In vivo quisinostat or decitabine treatment altered the expression of genes involved in immune pathways}

Using DAVID gene ontology (GO) software, the enrichment of the in vivo deregulated genes with a biological process was investigated [63, 64]. GO analysis showed a significant enrichment of genes involved in immune regulation, metabolism/homeostasis, development and differentiation, cytoskeleton/migration, regulation of gene expression and cell death (Supplementary Table S5). The hierarchical clustering of the co-enriched gene signatures is shown in Figure 4 and 5. Looking to the genes included in the scores in more detail showed that
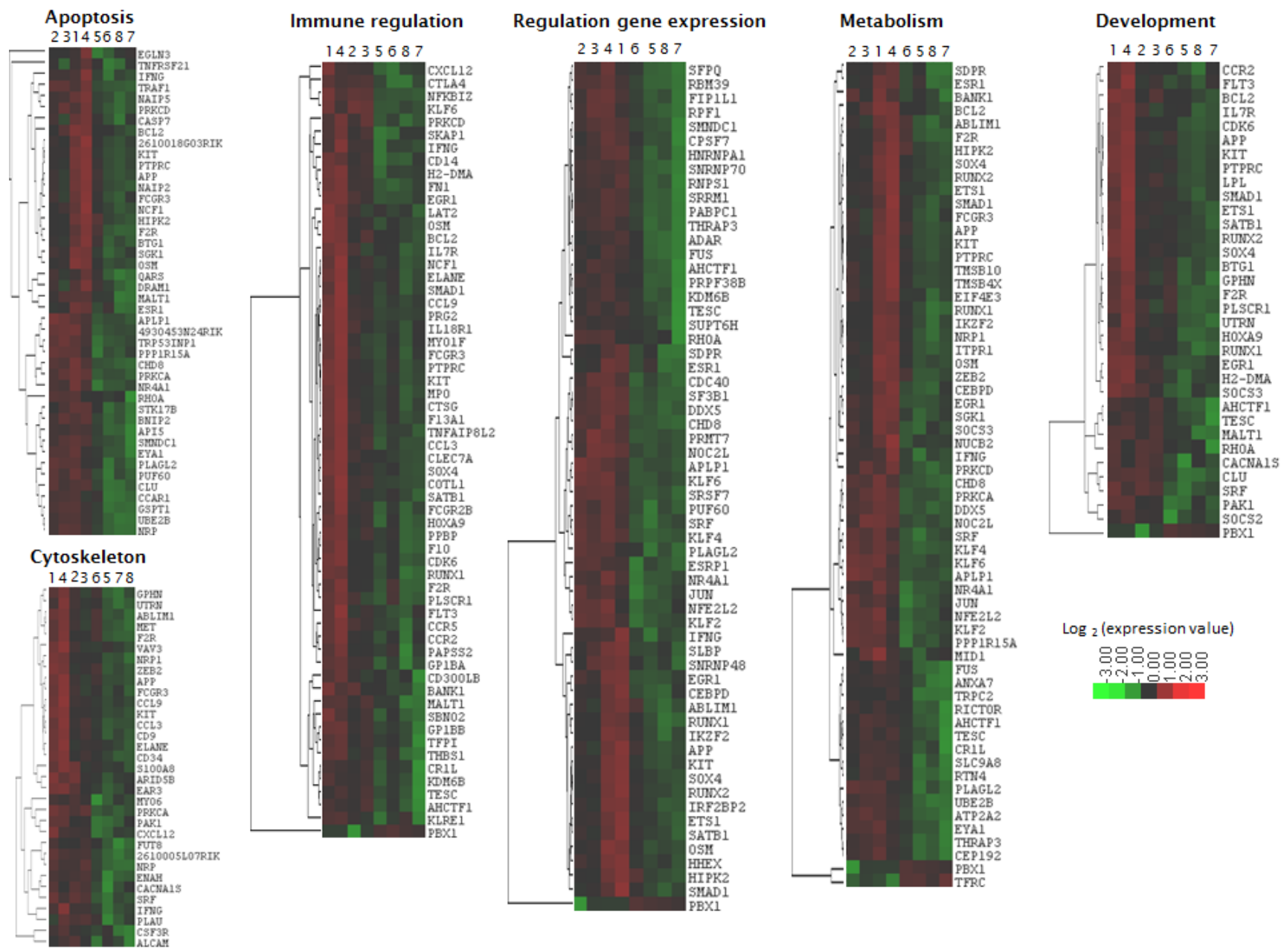

Figure 4: Heatmap of quisinostat-deregulated genes with overlapping functions identified by GO analysis and Reactome. Hierarchical clusters were made using Cluster and Treeview. Sample 1-4: quisinostat. Sample 5-8: vehicle. 
these genes were dispersed across all the different enriched GO sets. STRING protein network analysis confirmed the GO analysis and showed network interactions linked with immune cell regulation, cell death pathways and metabolism (Supplementary Figure S2, S3) [65]. Reactome pathway analysis revealed that after quisinostat treatment, there were several enriched gene sets and these were associated with growth factor signaling including tumor necrosis factor (TNF), TNF-related apoptosisinducing ligand (TRAIL), interferon-gamma (IFN- $\gamma$ ), interleukin-1 (IL-1), IL-2, IL-12, bone morphogenetic protein (BMP) and transforming growth factor beta (TGF- $\beta$ ). In addition, several signaling pathways showed enrichment of deregulated genes and include p38/MAPK, PI3K/Akt, SMAD, eIF4e, proteoglycan and integrin signaling (Supplementary Table S6).

Of particular interest, GO analysis, Reactome and STRING commonly identified a significant enrichment of genes linked with immune pathways. This immune pathway gene signature was characterized by genes encoding for proteins involved in lymphocyte activation and proliferation, immune-effector processes and T-helper-1 development as depicted by Reactome. Using Pathway-Guide, we found that the gene signature is built up by genes involved in chemokine signaling, cytokine interactions, phagocytosis, T-cell receptor and natural-killer (NK) cell signaling (Supplementary Table S7). The signature includes genes coding for chemokines (CXCL12, PBPB, CCL9, CCL3), chemokine receptors $(C C R 5, C C R 2)$, cytokines $(I F N G, O S M)$ and cytokine receptors (IL7R, IL18R1, KIT, FLT3, CSF1R, $C S F 3 R, M E T, T N F R S F 12)$. Genes encoding for proteins involved in lymphocyte activation include co-inhibitory proteins (CTLA4, CTLA2A, CTLA2B), co-stimulatory proteins $(P T P R C)$, antigen-presenting protein (H2$D M A)$, lymphocyte activation marker $(C D 69)$, monocyte marker (CD14), transcription factors (RUNX1, $P B X 1$, SMAD1, HOXA9, NFKBIZ, JUN, KLFO) and NK-cell inhibitory receptors (KLRD1, KLRA7). Genes encoding for proteins associated with immune-effector responses include phagocytose receptors (FCGR3, FCGR2B), phagocytosis mediators ( $P R K C A, P R K C D)$, extracellular matrix (ECM) component FN1 and its receptor ITGA5 and more downstream regulators (PAK1, RHOA, VAV3, IQGAP2, ENAH, APCRB, TMSB4X, DIAP1) involved in actin polymerization, adherens junctions and stress fibers polymerization (Figure 4, Supplementary Table S5, S6, $\mathrm{S} 7)$. Thus, in vivo treatment with quisinostat induced a broad transcriptional response within the tumor cells with a significant deregulation of genes encoding for proteins involved in immune regulation pathways.

\section{DISCUSSION}

To gain insight into the in vivo transcriptional response towards epigenetic modulating agents, we treated the syngeneic immunocompetent murine 5T33MM model with sub-lethal doses of the DNMTi decitabine and the HDACi quisinostat. First, in vivo treatment identified several deregulated genes with a prognostic value in the

\section{Regulation gene expression}

21346578

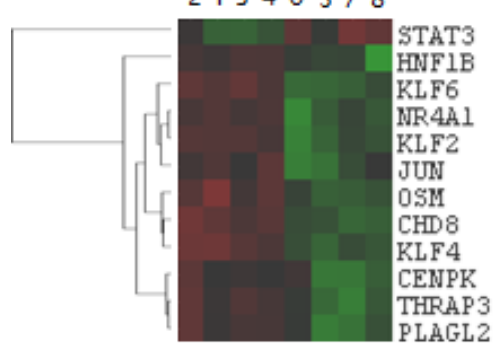

$\log _{2}$ (expression value)

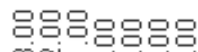

1.

\section{Immune regulation}

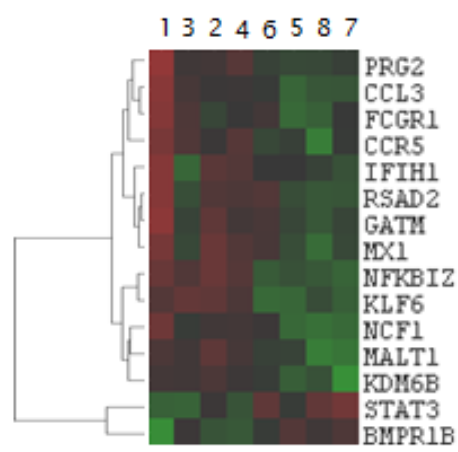

Metabolism

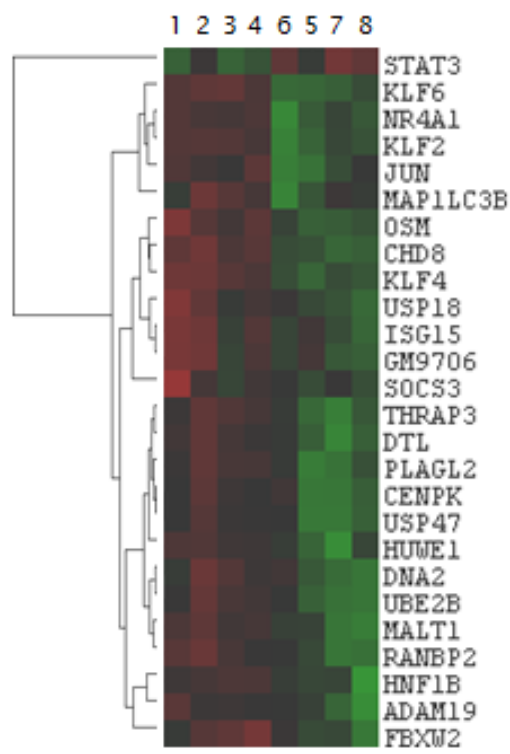

Figure 5: Heatmap of decitabine-deregulated genes with overlapping functions identified by GO analysis and Reactome. Hierarchical clusters were made using Cluster and Treeview. Sample 1-4: decitabine. Sample 5-8: vehicle. 
HM-cohort allowing the development of gene expressionbased risk scores. In accordance with our previous work in HMCL, both the Mu-DM and Mu-HA score were found to have a prognostic value for OS in two tested independent $\mathrm{MM}$ cohorts [35, 59]. In line, both the Mu-DM and $\mathrm{Mu}-$ HA score were an independent variable for prognosis of OS together with $\mathrm{t}(4 ; 14)$ in the HM-cohort but not in the TT2-cohort after multivariate COX analysis. In addition, the $\mathrm{Mu}-\mathrm{HA}$ and $\mathrm{Mu}-\mathrm{DM}$ score were independent of the previous published HA- and DM score in the HM cohort $[35,59]$. In addition, we showed that the Mu-HA score is predictive for overall survival of relapsed patients treated with bortezomib and further confirmed that gene expression profiling is useful for the prediction of outcome of newly diagnosed and relapsed patients [66]. The predictive power of the scores for treatment response was limited as the Mu-HA score had a low specificity of prediction for response to bortezomib and we did not identify a significant association between the $\mathrm{Mu}-\mathrm{DM}$ or $\mathrm{Mu}-\mathrm{HA}$ score and response to highdose conditioning chemotherapy and autologous stem cell transplantation. This confirms recently published data that gene expression profiling alone is not sufficient for predicting treatment response $[67,68]$. Overall, these data show the translation of gene signatures obtained after in vivo treatment of mice with epigenetic modulating agents that can be used to predict overall survival of previously untreated and relapsed MM patients. This furthermore validates the use of the 5T33MM model for evaluating the response towards epigenetic modulating agents and provides the framework for testing other epigenetic modulating agents with other or more specific targets.

Subsequently, we studied which factor(s) are responsible for the separation of MM patients. The observation that patients from the "PR" MM subgroup linked with a bad prognosis have higher $\mathrm{Mu}-\mathrm{DM}$ and/or $\mathrm{Mu}-\mathrm{HA}$ scores compared to all other subgroups indicates an association of high risk with proliferation and is in line with the results of the in vitro obtained DM- and HA-score [35, 59, 69]. The gradual higher score values in the GPI ${ }^{\text {high }}$ and GPI ${ }^{\text {medium }}$ group compared to the GPI ${ }^{\text {low }}$ group furthermore confirm the link between a high score and high proliferation [5]. We also compared transitional populations from memory B-cells to plasma cells for their score values. Pre-plasmablasts and plasmablasts are characterized by a higher proliferation rate compared to memory B-cells, early plasma cells and BMPCs [62, 70]. In addition, HMLCs were developed from primary MM samples which escaped the BM dependency and are highly proliferative $[58,71]$. Our observation that preplasmablasts and HMCL displayed the highest Mu-DM and $\mathrm{Mu}-\mathrm{HA}$ scores again indicates a link between a high score and proliferation. Overall, this validates our earlier work with the DM-score and HA-score [35, 59, 69] and suggests an association between the expression levels of epigenetically regulated genes and a high risk linked with a high proliferative and immature plasma cell phenotype.

Recently, the existence of plasma cell progenitors that recapitulate the different maturation stages of plasma cell differentiation was described within the BM of MM patients $[62,70]$ and was associated with proteasome inhibitor resistance $[61,72]$. MM progenitors including B cells and pre-plasmablasts were found to survive treatment with proteasome inhibitors and were significantly enriched in MM patients refractory to bortezomib treatment. These Xbp1s negative pre-plasmablastic cells are characterized by a diminished endoplasmic reticulum stress and thus resistance to proteasome inhibitors since they are not committed to high Ig production $[72,73]$. Furthermore, plasmablastic progenitors have been described to overexpress epigenetic regulators, compared to mature plasma cells, suggesting that transitions in plasma cell differentiation stages could be linked to epigenetic plasticity [61]. Thus, HDACi or DNMTi combined treatment could influence the plasticity of plasma cell progenitors and potentially target tumor progenitors that contribute to treatment failure in MM. Moreover, the scores presented here may be useful to predict the presence of such immature plasma cell populations.

In line with previous in vitro gene-expression profiling studies, we found associations of in vivo HDACi- and DNMTi-deregulated genes with biogenesis, cytoskeletal organization and immunological pathways [20, 35, 59]. In particular, we provide evidence that quisinostat (and to a lesser extend decitabine) induces tumoral transcriptional changes of genes involved in immune response pathways, namely lymphocyte activation and proliferation, immune-effector processes and T-helper-1 development. The immune system is suppressed in MM and studies focusing on reversing the suppressive state to boost immune-mediated antitumor responses are ongoing [74]. Emerging evidence indicates that epigenetics plays an important role in various aspects of the immune system including cytokine production, dendritic cell activation, plasticity of CD4+ T cells, regulatory $\mathrm{T}$ cell function and plasma cell differentiation $[75,76]$. In line, recent pre-clinical work has demonstrated that epigenetic modulating agents have immunomodulatory effects. West et al. suggested that HDACi require an intact immune system for long term effects in murine cancer models [43]. The authors demonstrated that the HDACi vorinostat mediated immunogenic anti-tumor effects through IFN- $\gamma$ production by B-cells [77]. These effects were moreover enhanced by $\alpha$-galactosylceramide and may imply a role for NKT cells $[77,78]$. Vorinostat was also shown to possess immunomodulatory properties in isolated peripheral blood mononuclear cells and in mice after lipopolysaccharide exposure [79]. Interestingly, in AML patients, panobinostat in combination with azacytidine decreased TNFR2+ regulatory T-cell populations associated with IFN- $\gamma$ and IL-2 induction [80]. Taken 
together, our data and work by others supports the use of HDACi in combination with immunomodulatory therapies such as IMiDs, transplantation, humoral or cellular/peptide vaccines as recently suggested $[77,81]$.

So far, a few pre-clinical studies demonstrated combinatory effects of HDACi and IMiDs in MM but lack mechanistic evidence. Vorinostat in combination with the thalidomide derivate IMiD1 showed combinatory effects in vitro [82]. In addition, panobinostat enhanced anti-MM effects of lenalidomide and dexamethasone in vitro and in vivo [83]. Vorinostat or panobinostat have been shown to present synergistic effects in combination with the immune cell stimulating antibodies anti-CD40 and anti-CD137 in immunocompetent models of mammary, renal and colon carcinoma [84]. Very recently, in a murine melanoma model, panobinostat was demonstrated to synergize with an adoptive T-cell transfer leading to systemic immune responses to reduce melanoma tumor burden [81]. Panobinostat influenced T-cell populations and systemic cytokine production independent from the presence of tumor [81]. The above work suggests the potential of combining HDACi with immunotherapy strategies. Nevertheless, future pre-clinical in vivo work is mandatory to further address this possibility. Regarding safety issues, it was only recently shown that the combination of vorinostat and lenalidomide plus dexamethasone is well tolerated in MM patients in a phase I clinical trial [85].

In conclusion, in vivo treatment of MM cells with epigenetic modulating agents results in a transcriptional response that can be linked to prognosis. This prognostic signature was used to construct a gene expression based risk score allowing risk stratification of newly diagnosed patients. In addition, HDACi treatment (and to a lesser extent DNMTi) resulted in a wide transcriptional response involving overlapping gene signatures mainly mediating immune response. This indicates that transcriptional immune regulation is an important in vivo biological response of tumor cells towards HDACi and supports the rationale for the combination of $\mathrm{HDACi}$ and immunomodulatory therapies.

\section{MATERIALS AND METHODS}

\section{Drugs}

Decitabine (Dacogen) and quisinostat (JNJ26481585) were kindly provided by Johnson \& Johnson (Beerse, Belgium) and used as a filter sterilized 10\% hydroxypropyl-cyclodextran suspension.

\section{Treatment and isolation of murine 5T33MM cells}

C57BL/KaLwRij mice were purchased from Harlan CPB (Horst, The Netherlands). Mice were housed according to the conditions approved by the Ethical Committee for Animal Experiments of the Vrije Universiteit Brussel (license no. LA1230281). The 5T33MM model was maintained as previously described [86]. At day 0, naive C57BL/KaLwRij mice were injected with $5 \times 10^{5} 5 \mathrm{~T} 33 \mathrm{MM}$ cells. At established disease (day 16), mice were treated with decitabine $(0.2 \mathrm{mg} / \mathrm{kg})$ (intraperitoneal injection, daily) or quisinostat $(1.5 \mathrm{mg} /$ $\mathrm{kg}$ ) (subcutaneous injection, once every other day). After 5 days, mice were sacrified. Bone marrow was isolated from hind legs and subjected to red blood cell lysis. For mRNA analysis, tumor cells were purified by depletion of CD11b + contaminating cells. An overall mean purity of plasma cells of above $90 \%$ was obtained (Supplementary Figure S1C). Cytospins were made before and after depletion to count the percentage of plasma cells as described previously [32].

\section{Gene expression profiling}

Samples with more than $95 \%$ plasma cells $(\mathrm{N}=4$ in each group) were used for RNA isolation using the RNeasy Kit (Qiagen, Venlo, The Netherlands). RNA was further processed and hybridized to the Mouse Genome 4302.0 Array (Affymetrix, Santa Clara, CA, USA) as described in Moreaux et. al [35]. Microarray data are available at ArrayExpress database (Accession number: E-MTAB-3178).

\section{Microarray data of primary multiple myeloma cells and human myeloma cell lines}

Affymetrix data of two independent cohorts of previously untreated MM patients was used. The training cohort consists of $206 \mathrm{MM}$ patients and is termed the Heidelberg-Montpellier (HM)-cohort. This cohort also includes 7 bone marrow plasma cell (BMPC) samples from healthy donors. The samples were obtained after written informed consent in accordance with the Declaration of Helsinki and after approval of the ethics committee of Montpellier and Heidelberg. These data are publically available through ArrayExpress database (E-MTAB-372). The validation cohort contains 345 MM patients from the University of Arkansas for Medical Sciences (UAMS, Little Rock, AR, USA) and is termed the TT2-cohort. These data can be accessed at the online Gene Expression Omnibus (GSE2658). In the HM study, patients underwent front line high-dose conditioning chemotherapy with $200 \mathrm{mg} / \mathrm{m}^{2}$ melphalan and autologous stem cell transplantation $[5,56]$. In the UAMS study, patients received thalidomide or placebo in combination with 4 consecutive induction cycles containing (i) vincristine + doxorubicin + dexamethasone, (ii) cyclophosphamide + etoposide + cisplatin + dexamethasone, (iii) cyclophosphamide + doxorubicin, 
and (iv) cyclophosphamide + etoposide + cisplatin + dexamethasone (corresponding to total therapy 2 (TT2)). This was followed by high-dose melphalan and autologous stem cell transplantation $[54,87,88]$. The presence of cytogenetic abnormalities was evaluated by iFISH in the patients of the HM cohort. For TT2, the presence of $\mathrm{t}(4 ; 14)$ was predicted by MMSET spike expression [89]. We also used Affymetrix data of 152 relapsed MM patients subsequently treated with bortezomib (GSE9782) from the study by Mulligan et al. [57]. The clinical characteristics of the cohorts have been described previously and are summarized in Supplementary Table S8 [54-57]. In addition, we used the Affymetrix data of 40 human myeloma cell lines (HMCLs) stored in the ArrayExpress database (E-TABM-937 and E-TABM-1088) [58]. The derivation of the HMCLs as well as their phenotypic and molecular characteristics were previously published [58].

\section{Statistical analysis and bio-informatics}

Normalization of gene expression data was done by the MAS5 algorithm (scale 100) and analyzed by Significance of Microarray Analysis (SAM) [90] and bioinformatics platforms RAGE and Amazonia [91, 92]. The Benjamini-Hochberg multiple testing corrections were done for estimation of false discovery rate (FDR). The prognostic value of the genes in terms of overall survival (OS) was determined using the Maxstat $\mathrm{R}$ package. Significance was determined by log-rank test followed by Benjamin-Hochberg multiple testing correction. To combine the prognostic value of all those genes, a score was constructed and termed the murine DNA methylation (Mu-DM) and histone acetylation (Mu-HA) score. The scores are the sum of the Cox $\beta$-coefficients of the human orthologs of the decitabine- or quisinostat-deregulated genes with prognostic value in the training cohort, weighted by + or -1 if the patients' MM cell MAS5 signal for any given gene is above or below the probe set Maxstat cutoff of this gene $[35,59,89]$. Results were plotted using the Kaplan-Meier method. Multivariate analysis of the scores was done using Cox proportional hazard model. The above analyses were performed using $\mathrm{R} 2.15 .1$ and Bioconductor 2.0 software. Gene ontology (GO) analysis was done by the online Database for Annotation, Visualization and Integrated Discovery (DAVID) [63, 64]. Pathway analysis was conducted by Reactome software, Pathway-Guide and STRING analysis.

\section{ACKNOWLEDGMENTS}

We thank Carine Seynaeve for her expert technical assistance. Decitabine and quisinostat were kindly provided by Johnson \& Johnson (Beerse, Belgium).

This work is funded by a Brian D. Novis research grant of the International Myeloma Foundation, Vlaamse
Liga tegen Kanker, Stichting tegen kanker, Fonds voor Wetenschappelijk Onderzoek, ARC (SF120121205949, Paris, France), ANR emergence (ETTMM), CRLR grant (R14026FF), $7^{\text {th }}$ EU-framework program "OverMyR", the German Research Foundation (DFG; SFB/TRR79) and the Federal Ministry of Education and Research (BMBF; CAMPSIMM and CLIOMMICS), Bonn, Germany. Elke De Bruyne and Els Van Valckenborgh are fellows of FWO-Vlaanderen. This work was published with the support of the University Foundation Belgium.

\section{Conflict-of-interest disclosure}

Dirk Hose and Anja Seckinger receive research support from Novartis. The other authors declare no competing financial interests.

\section{REFERENCES}

1. Lemaire M, Deleu S, De Bruyne E, Van Valckenborgh E, Menu E, Vanderkerken K. The microenvironment and molecular biology of the multiple myeloma tumor. Adv Cancer Res. 2011; 110: 19-42.

2. Barlogie B, Tricot GJ, van Rhee F, Angtuaco E, Walker R, Epstein J, Shaughnessy JD, Jagannath S, Bolejack V, Gurley J, Hoering A, Vesole D, Desikan R, et al. Long-term outcome results of the first tandem autotransplant trial for multiple myeloma. Br J Haematol. 2006; 135: 158-64.

3. Avet-Loiseau H, Attal M, Moreau P, Charbonnel C, Garban F, Hulin C, Leyvraz S, Michallet M, Yakoub-Agha I, Garderet L, Marit G, Michaux L, Voillat L, et al. Genetic abnormalities and survival in multiple myeloma: the experience of the Intergroupe Francophone du Myelome. Blood. 2007; 109: 3489-95.

4. Decaux O, Lode L, Magrangeas F, Charbonnel C, Gouraud W, Jezequel P, Attal M, Harousseau JL, Moreau P, Bataille R, Campion L, Avet-Loiseau H, Minvielle S. Prediction of survival in multiple myeloma based on gene expression profiles reveals cell cycle and chromosomal instability signatures in high-risk patients and hyperdiploid signatures in low-risk patients: a study of the Intergroupe Francophone du Myelome. J Clin Oncol. 2008; 26: 4798-805.

5. Hose D, Reme T, Hielscher T, Moreaux J, Messner T, Seckinger A, Benner A, Shaughnessy JD, Jr., Barlogie B, Zhou Y, Hillengass J, Bertsch U, Neben K, et al. Proliferation is a central independent prognostic factor and target for personalized and risk-adapted treatment in multiple myeloma. Haematologica. 2011; 96: 87-95.

6. Neben K, Jauch A, Hielscher T, Hillengass J, Lehners N, Seckinger A, Granzow M, Raab MS, Ho AD, Goldschmidt H, Hose D. Progression in smoldering myeloma is independently determined by the chromosomal abnormalities del(17p), t(4;14), gain 1q, hyperdiploidy, and tumor load. J Clin Oncol. 2013; 31: 4325-32. 
7. Reme T, Hose D, Theillet C, Klein B. Modeling risk stratification in human cancer. Bioinformatics. 2013; 29: 1149-57.

8. Shaughnessy JD, Jr., Zhan F, Burington BE, Huang Y, Colla S, Hanamura I, Stewart JP, Kordsmeier B, Randolph C, Williams DR, Xiao Y, Xu H, Epstein J, et al. A validated gene expression model of high-risk multiple myeloma is defined by deregulated expression of genes mapping to chromosome 1. Blood. 2007; 109: 2276-84.

9. Hose D, Moreaux J, Meissner T, Seckinger A, Goldschmidt H, Benner A, Mahtouk K, Hillengass J, Reme T, De Vos J, Hundemer M, Condomines M, Bertsch U, et al. Induction of angiogenesis by normal and malignant plasma cells. Blood. 2009; 114: 128-43.

10. Seckinger A, Meissner $\mathrm{T}$, Moreaux J, Depeweg D, Hillengass J, Hose K, Reme T, Rosen-Wolff A, Jauch A, Schnettler R, Ewerbeck V, Goldschmidt H, Klein B, et al. Clinical and prognostic role of annexin A2 in multiple myeloma. Blood. 2012; 120: 1087-94.

11. Seckinger A, Meissner T, Moreaux J, Goldschmidt H, Fuhler GM, Benner A, Hundemer M, Reme T, Shaughnessy JD, Jr., Barlogie B, Bertsch U, Hillengass J, Ho AD, et al. Bone morphogenic protein 6: a member of a novel class of prognostic factors expressed by normal and malignant plasma cells inhibiting proliferation and angiogenesis. Oncogene. 2009.

12. Engelhardt M, Terpos E, Kleber M, Gay F, Wasch R, Morgan G, Cavo M, van de Donk N, Beilhack A, Bruno B, Johnsen HE, Hajek R, Driessen C, et al. European Myeloma Network recommendations on the evaluation and treatment of newly diagnosed patients with multiple myeloma. Haematologica. 2014; 99: 232-42.

13. Reeder CB, Reece DE, Kukreti V, Mikhael JR, Chen C, Trudel S, Laumann K, Vohra H, Fonseca R, Bergsagel PL, Leis JF, Tiedemann R, Stewart AK. Long-term survival with cyclophosphamide, bortezomib and dexamethasone induction therapy in patients with newly diagnosed multiple myeloma. Br J Haematol. 2014; 167: 563-5.

14. Usmani SZ, Crowley J, Hoering A, Mitchell A, Waheed S, Nair B, AlSayed Y, Vanrhee F, Barlogie B. Improvement in long-term outcomes with successive Total Therapy trials for multiple myeloma: are patients now being cured? Leukemia. 2013; 27: 226-32.

15. van Rhee F, Giralt S, Barlogie B. The future of autologous stem cell transplantation in myeloma. Blood. 2014; 124: 328-33.

16. Maes K, Menu E, Van Valckenborgh E, Van Riet I, Vanderkerken K, De Bruyne E. Epigenetic modulating agents as a new therapeutic approach in multiple myeloma. Cancers. 2013; 5: 430-61.

17. Smith EM, Boyd K, Davies FE. The potential role of epigenetic therapy in multiple myeloma. Br J Haematol. 2010; 148: 702-13.

18. Dimopoulos K, Gimsing P, Gronbaek K. The role of epigenetics in the biology of multiple myeloma. Blood Cancer J. 2014; 4: e207.

19. De Bruyne E, Bos TJ, Asosingh K, Vande Broek I, Menu E, Van Valckenborgh E, Atadja P, Coiteux V, Leleu X, Thielemans K, Van Camp B, Vanderkerken K, Van Riet I. Epigenetic silencing of the tetraspanin CD9 during disease progression in multiple myeloma cells and correlation with survival. Clin Cancer Res. 2008; 14: 2918-26.

20. Heller G, Schmidt WM, Ziegler B, Holzer S, Mullauer L, Bilban M, Zielinski CC, Drach J, Zochbauer-Muller S. Genome-wide transcriptional response to 5-aza-2'deoxycytidine and trichostatin a in multiple myeloma cells. Cancer Res. 2008; 68: 44-54.

21. Stanganelli C, Arbelbide J, Fantl DB, Corrado C, Slavutsky I. DNA methylation analysis of tumor suppressor genes in monoclonal gammopathy of undetermined significance. Ann Hematol. 2010; 89: 191-9.

22. Walker BA, Wardell CP, Chiecchio L, Smith EM, Boyd KD, Neri A, Davies FE, Ross FM, Morgan GJ. Aberrant global methylation patterns affect the molecular pathogenesis and prognosis of multiple myeloma. Blood. 2011; 117: 553-62.

23. Kaiser MF, Johnson DC, Wu P, Walker BA, Brioli A, Mirabella F, Wardell CP, Melchor L, Davies FE, Morgan GJ. Global methylation analysis identifies prognostically important epigenetically inactivated tumor suppressor genes in multiple myeloma. Blood. 2013; 122: 219-26.

24. Heuck CJ, Mehta J, Bhagat T, Gundabolu K, Yu Y, Khan S, Chrysofakis G, Schinke C, Tariman J, Vickrey E, Pulliam $\mathrm{N}$, Nischal S, Zhou L, et al. Myeloma is characterized by stage-specific alterations in DNA methylation that occur early during myelomagenesis. J Immunol. 2013; 190: 296675.

25. Bollati V, Fabris S, Pegoraro V, Ronchetti D, Mosca L, Deliliers GL, Motta V, Bertazzi PA, Baccarelli A, Neri A. Differential repetitive DNA methylation in multiple myeloma molecular subgroups. Carcinogenesis. 2009; 30: 1330-5.

26. Chi P, Allis CD, Wang GG. Covalent histone modifications-miswritten, misinterpreted and mis-erased in human cancers. Nat Rev Cancer. 2010; 10: 457-69.

27. Marango J, Shimoyama M, Nishio H, Meyer JA, Min DJ, Sirulnik A, Martinez-Martinez Y, Chesi M, Bergsagel PL, Zhou MM, Waxman S, Leibovitch BA, Walsh MJ, et al. The MMSET protein is a histone methyltransferase with characteristics of a transcriptional corepressor. Blood. 2008; 111: 3145-54.

28. Chapman MA, Lawrence MS, Keats JJ, Cibulskis K, Sougnez C, Schinzel AC, Harview CL, Brunet JP, Ahmann GJ, Adli M, Anderson KC, Ardlie KG, Auclair $\mathrm{D}$, et al. Initial genome sequencing and analysis of multiple myeloma. Nature. 2011; 471: 467-72.

29. van Haaften G, Dalgliesh GL, Davies H, Chen L, Bignell G, Greenman C, Edkins S, Hardy C, O’Meara S, Teague 
J, Butler A, Hinton J, Latimer C, et al. Somatic mutations of the histone H3K27 demethylase gene UTX in human cancer. Nat Genet. 2009; 41: 521-3.

30. Dawson MA, Kouzarides T. Cancer epigenetics: from mechanism to therapy. Cell. 2012; 150: 12-27.

31. Deleu S, Lemaire M, Arts J, Menu E, Van Valckenborgh E, King P, Vande Broek I, De Raeve H, Van Camp B, Croucher P, Vanderkerken K. The effects of JNJ-26481585, a novel hydroxamate-based histone deacetylase inhibitor, on the development of multiple myeloma in the 5T2MM and 5T33MM murine models. Leukemia. 2009; 23: 1894903.

32. Deleu S, Lemaire M, Arts J, Menu E, Van Valckenborgh E, Vande Broek I, De Raeve H, Coulton L, Van Camp B, Croucher P, Vanderkerken K. Bortezomib alone or in combination with the histone deacetylase inhibitor JNJ26481585: effect on myeloma bone disease in the 5T2MM murine model of myeloma. Cancer Res. 2009; 69: 5307-11.

33. Kaufman JL, Fabre C, Lonial S, Richardson PG. Histone deacetylase inhibitors in multiple myeloma: rationale and evidence for their use in combination therapy. Clin Lymphoma Myeloma Leuk. 2013; 13: 370-6.

34. Maes K, De Smedt E, Lemaire M, De Raeve H, Menu E, Van Valckenborgh E, McClue S, Vanderkerken K, De Bruyne E. The role of DNA damage and repair in decitabine-mediated apoptosis in multiple myeloma. Oncotarget. 2014; 5: 3115-29.

35. Moreaux J, Reme T, Leonard W, Veyrune JL, Requirand G, Goldschmidt H, Hose D, Klein B. Development of gene expression-based score to predict sensitivity of multiple myeloma cells to DNA methylation inhibitors. Mol Cancer Ther. 2012; 11: 2685-92.

36. Niesvizky R, Ely S, Mark T, Aggarwal S, Gabrilove JL, Wright JJ, Chen-Kiang S, Sparano JA. Phase 2 trial of the histone deacetylase inhibitor romidepsin for the treatment of refractory multiple myeloma. Cancer. 2011; 117: 336-42.

37. Richardson P, Mitsiades C, Colson K, Reilly E, McBride L, Chiao J, Sun L, Ricker J, Rizvi S, Oerth C, Atkins B, Fearen I, Anderson K, et al. Phase I trial of oral vorinostat (suberoylanilide hydroxamic acid, SAHA) in patients with advanced multiple myeloma. Leuk Lymphoma. 2008; 49: 502-7.

38. Wolf JL, Siegel D, Goldschmidt H, Hazell K, Bourquelot PM, Bengoudifa BR, Matous J, Vij R, de MagalhaesSilverman M, Abonour R, Anderson KC, Lonial S. Phase II trial of the pan-deacetylase inhibitor panobinostat as a single agent in advanced relapsed/refractory multiple myeloma. Leuk Lymphoma. 2012; 53: 1820-3.

39. Dimopoulos M, Siegel DS, Lonial S, Qi J, Hajek R, Facon T, Rosinol L, Williams C, Blacklock H, Goldschmidt H, Hungria V, Spencer A, Palumbo A, et al. Vorinostat or placebo in combination with bortezomib in patients with multiple myeloma (VANTAGE 088): a multicentre, randomised, double-blind study. Lancet Oncol. 2013; 14: $1129-40$
40. San-Miguel JF, Hungria VT, Yoon SS, Beksac M, Dimopoulos MA, Elghandour A, Jedrzejczak WW, Gunther A, Nakorn TN, Siritanaratkul N, Corradini P, Chuncharunee S, Lee JJ, et al. Panobinostat plus bortezomib and dexamethasone versus placebo plus bortezomib and dexamethasone in patients with relapsed or relapsed and refractory multiple myeloma: a multicentre, randomised, double-blind phase 3 trial. Lancet Oncol. 2014; 15: 1195 206.

41. Offidani M, Polloni C, Cavallo F, Liberati AM, Ballanti S, Pulini S, Catarini M, Alesiani F, Corvatta L, Gentili S, Caraffa P, Boccadoro M, Leoni P, et al. Phase II study of melphalan, thalidomide and prednisone combined with oral panobinostat in patients with relapsed/refractory multiple myeloma. Leuk Lymphoma. 2012; 53: 1722-7.

42. Tsai HC, Li H, Van Neste L, Cai Y, Robert C, Rassool FV, Shin JJ, Harbom KM, Beaty R, Pappou E, Harris J, Yen RW, Ahuja N, et al. Transient low doses of DNAdemethylating agents exert durable antitumor effects on hematological and epithelial tumor cells. Cancer Cell. 2011; 21: 430-46.

43. West AC, Smyth MJ, Johnstone RW. The anticancer effects of HDAC inhibitors require the immune system. Oncoimmunology. 2014; 3: e27414.

44. Richardson PG, Mitsiades CS, Laubach JP, Hajek R, Spicka I, Dimopoulos MA, Moreau P, Siegel DS, Jagannath S, Anderson KC. Preclinical data and early clinical experience supporting the use of histone deacetylase inhibitors in multiple myeloma. Leuk Res. 2013; 37: 829-37.

45. Andrews SW, Kabrah S, May JE, Donaldson C, Morse HR. Multiple myeloma: the bone marrow microenvironment and its relation to treatment. Br J Biomed Sci. 2013; 70: 110-20.

46. Burington B, Barlogie B, Zhan F, Crowley J, Shaughnessy JD, Jr. Tumor cell gene expression changes following shortterm in vivo exposure to single agent chemotherapeutics are related to survival in multiple myeloma. Clin Cancer Res. 2008; 14: 4821-9.

47. Chauhan D, Singh AV, Brahmandam M, Carrasco R, Bandi M, Hideshima T, Bianchi G, Podar K, Tai YT, Mitsiades C, Raje N, Jaye DL, Kumar SK, et al. Functional interaction of plasmacytoid dendritic cells with multiple myeloma cells: a therapeutic target. Cancer Cell. 2009; 16: 309-23.

48. Pratt G. Histone deacetylase inhibitors in multiple myeloma. Lancet Oncol. 2013; 14: 1038-9.

49. De Bruyne E, Andersen TL, De Raeve H, Van Valckenborgh E, Caers J, Van Camp B, Delaisse JM, Van Riet I, Vanderkerken K. Endothelial cell-driven regulation of CD9 or motility-related protein-1 expression in multiple myeloma cells within the murine 5T33MM model and myeloma patients. Leukemia. 2006; 20: 1870-9.

50. Menu E, Jernberg-Wiklund $H$, De Raeve $H$, De Leenheer E, Coulton L, Gallagher O, Van Valckenborgh E, Larsson O, Axelson M, Nilsson K, Van Camp B, Croucher P, Vanderkerken K. Targeting the IGF-1R using picropodophyllin in the therapeutical 5T2MM mouse model 
of multiple myeloma: beneficial effects on tumor growth, angiogenesis, bone disease and survival. Int J Cancer. 2007; 121: 1857-61.

51. Van Valckenborgh E, Schouppe E, Movahedi K, De Bruyne E, Menu E, De Baetselier P, Vanderkerken K, Van Ginderachter JA. Multiple myeloma induces the immunosuppressive capacity of distinct myeloid-derived suppressor cell subpopulations in the bone marrow. Leukemia. 2012; 26: 2424-8.

52. Vanderkerken K, Asosingh K, Croucher P, Van Camp B. Multiple myeloma biology: lessons from the 5TMM models. Immunol Rev. 2003; 194: 196-206.

53. Arts J, King P, Marien A, Floren W, Belien A, Janssen L, Pilatte I, Roux B, Decrane L, Gilissen R, Hickson I, Vreys V, Cox E, et al. JNJ-26481585, a novel "second-generation" oral histone deacetylase inhibitor, shows broad-spectrum preclinical antitumoral activity. Clin Cancer Res. 2009; 15: 6841-51.

54. Barlogie B, Tricot G, Rasmussen E, Anaissie E, van Rhee F, Zangari M, Fassas A, Hollmig K, Pineda-Roman M, Shaughnessy J, Epstein J, Crowley J. Total therapy 2 without thalidomide in comparison with total therapy 1: role of intensified induction and posttransplantation consolidation therapies. Blood. 2006; 107: 2633-8.

55. Goldschmidt H, Sonneveld P, Cremer FW, van der Holt B, Westveer P, Breitkreutz I, Benner A, Glasmacher A, Schmidt-Wolf IG, Martin H, Hoelzer D, Ho AD, Lokhorst HM. Joint HOVON-50/GMMG-HD3 randomized trial on the effect of thalidomide as part of a high-dose therapy regimen and as maintenance treatment for newly diagnosed myeloma patients. Ann Hematol. 2003; 82: 654-9.

56. Hose D, Reme T, Meissner T, Moreaux J, Seckinger A, Lewis J, Benes V, Benner A, Hundemer M, Hielscher T, Shaughnessy JD, Jr., Barlogie B, Neben K, et al. Inhibition of aurora kinases for tailored risk-adapted treatment of multiple myeloma. Blood. 2009; 113: 4331-40.

57. Mulligan G, Mitsiades C, Bryant B, Zhan F, Chng WJ, Roels S, Koenig E, Fergus A, Huang Y, Richardson P, Trepicchio WL, Broyl A, Sonneveld P, et al. Gene expression profiling and correlation with outcome in clinical trials of the proteasome inhibitor bortezomib. Blood. 2007; 109: 3177-88.

58. Moreaux J, Klein B, Bataille R, Descamps G, Maiga S, Hose D, Goldschmidt H, Jauch A, Reme T, Jourdan M, Amiot M, Pellat-Deceunynck C. A high-risk signature for patients with multiple myeloma established from the molecular classification of human myeloma cell lines. Haematologica. 2011; 96: 574-82.

59. Moreaux J, Reme T, Leonard W, Veyrune JL, Requirand G, Goldschmidt H, Hose D, Klein B. Gene expression-based prediction of myeloma cell sensitivity to histone deacetylase inhibitors. Br J Cancer. 2013; 109: 676-85.

60. Zhan F, Huang Y, Colla S, Stewart JP, Hanamura I, Gupta S, Epstein J, Yaccoby S, Sawyer J, Burington B, Anaissie E, Hollmig K, Pineda-Roman M, et al. The molecular classification of multiple myeloma. Blood. 2006; 108: 2020-8.

61. Chaidos A, Barnes CP, Cowan G, May PC, Melo V, Hatjiharissi E, Papaioannou M, Harrington H, Doolittle H, Terpos E, Dimopoulos M, Abdalla S, Yarranton H, et al. Clinical drug resistance linked to interconvertible phenotypic and functional states of tumor-propagating cells in multiple myeloma. Blood. 2012; 121: 318-28.

62. Jourdan M, Caraux A, De Vos J, Fiol G, Larroque M, Cognot C, Bret C, Duperray C, Hose D, Klein B. An in vitro model of differentiation of memory $\mathrm{B}$ cells into plasmablasts and plasma cells including detailed phenotypic and molecular characterization. Blood. 2009; 114: 5173-81.

63. Huang da W, Sherman BT, Lempicki RA. Systematic and integrative analysis of large gene lists using DAVID bioinformatics resources. Nat Protoc. 2009; 4: 44-57.

64. Huang da W, Sherman BT, Lempicki RA. Bioinformatics enrichment tools: paths toward the comprehensive functional analysis of large gene lists. Nucleic Acids Res. 2009; 37: 1-13.

65. Franceschini A, Szklarczyk D, Frankild S, Kuhn M, Simonovic M, Roth A, Lin J, Minguez P, Bork P, von Mering C, Jensen LJ. STRING v9.1: protein-protein interaction networks, with increased coverage and integration. Nucleic Acids Res. 2013; 41: D808-15.

66. Zhan F, Barlogie B, Mulligan G, Shaughnessy JD, Jr., Bryant B. High-risk myeloma: a gene expression based riskstratification model for newly diagnosed multiple myeloma treated with high-dose therapy is predictive of outcome in relapsed disease treated with single-agent bortezomib or high-dose dexamethasone. Blood. 2008; 111: 968-9.

67. Amin SB, Yip WK, Minvielle S, Broyl A, Li Y, Hanlon B, Swanson D, Shah PK, Moreau P, van der Holt B, van Duin M, Magrangeas F, Pieter Sonneveld P, et al. Gene expression profile alone is inadequate in predicting complete response in multiple myeloma. Leukemia. 2014; 28: 2229-34.

68. Meissner T, Seckinger A, Reme T, Hielscher T, Mohler T, Neben K, Goldschmidt H, Klein B, Hose D. Gene expression profiling in multiple myeloma--reporting of entities, risk, and targets in clinical routine. Clin Cancer Res. 2011; 17: 7240-7.

69. Moreaux J, Bruyer A, Veyrune JL, Goldschmidt H, Hose D, Klein B. DNA methylation score is predictive of myeloma cell sensitivity to 5-azacitidine. Br J Haematol. 2014; 164: 613-6.

70. Jourdan M, Caraux A, Caron G, Robert N, Fiol G, Reme T, Bollore K, Vendrell JP, Le Gallou S, Mourcin F, De Vos J, Kassambara A, Duperray C, et al. Characterization of a transitional preplasmablast population in the process of human B cell to plasma cell differentiation. J Immunol. 2011; 187: 3931-41.

71. Zhang XG, Gaillard JP, Robillard N, Lu ZY, Gu ZJ, Jourdan M, Boiron JM, Bataille R, Klein B. Reproducible obtaining 
of human myeloma cell lines as a model for tumor stem cell study in human multiple myeloma. Blood. 1994; 83: 365463.

72. Leung-Hagesteijn C, Erdmann N, Cheung G, Keats JJ, Stewart AK, Reece DE, Chung KC, Tiedemann RE. $\mathrm{Xbp} 1 \mathrm{~s}$-negative tumor $\mathrm{B}$ cells and pre-plasmablasts mediate therapeutic proteasome inhibitor resistance in multiple myeloma. Cancer Cell. 2013; 24: 289-304.

73. Orlowski RZ. Why proteasome inhibitors cannot ERADicate multiple myeloma. Cancer Cell. 2013; 24: 275 7.

74. Romano A, Conticello C, Cavalli M, Vetro C, La Fauci A, Parrinello NL, Di Raimondo F. Immunological Dysregulation in Multiple Myeloma Microenvironment. Biomed Res Int. 2014; 2014: 198539.

75. Suarez-Alvarez B, Baragano Raneros A, Ortega F, LopezLarrea C. Epigenetic modulation of the immune function: a potential target for tolerance. Epigenetics. 2013; 8: 694-702.

76. Villagra A, Sotomayor EM, Seto E. Histone deacetylases and the immunological network: implications in cancer and inflammation. Oncogene. 2010; 29: 157-73.

77. West AC, Mattarollo SR, Shortt J, Cluse LA, Christiansen AJ, Smyth MJ, Johnstone RW. An Intact Immune System Is Required for the Anticancer Activities of Histone Deacetylase Inhibitors. Cancer Research. 2013; 73: 7265 76.

78. Nur H, Fostier K, Aspeslagh S, Renmans W, Bertrand E, Leleu X, Favreau M, Breckpot K, Schots R, De Waele M, Van Valckenborgh E, De Bruyne E, Facon T, et al. Preclinical evaluation of invariant natural killer $\mathrm{T}$ cells in the 5T33 multiple myeloma model. PLoS ONE. 2013; 8: e65075.

79. Leoni F, Zaliani A, Bertolini G, Porro G, Pagani P, Pozzi P, Dona G, Fossati G, Sozzani S, Azam T, Bufler P, Fantuzzi $\mathrm{G}$, Goncharov I, et al. The antitumor histone deacetylase inhibitor suberoylanilide hydroxamic acid exhibits antiinflammatory properties via suppression of cytokines. Proc Natl Acad Sci U S A. 2002; 99: 2995-3000.

80. Govindaraj C, Tan P, Walker P, Wei A, Spencer A, Plebanski M. Reducing TNF receptor $2+$ regulatory $\mathrm{T}$ cells via the combined action of azacitidine and the HDAC inhibitor, panobinostat for clinical benefit in acute myeloid leukemia patients. Clin Cancer Res. 2014; 20: 724-35.

81. Lisiero DN, Soto H, Everson RG, Liau LM, Prins RM. The histone deacetylase inhibitor, LBH589, promotes the systemic cytokine and effector responses of adoptively transferred CD8+ T cells. J Immunother Cancer. 2014; 2: 8.

82. Mitsiades CS, Mitsiades NS, McMullan CJ, Poulaki V, Shringarpure R, Hideshima T, Akiyama M, Chauhan D, Munshi N, Gu X, Bailey C, Joseph M, Libermann TA, et al. Transcriptional signature of histone deacetylase inhibition in multiple myeloma: biological and clinical implications. Proc Natl Acad Sci U S A. 2004; 101: 540-5.

83. Ocio EM, Vilanova D, Atadja P, Maiso P, Crusoe E,
Fernandez-Lazaro D, Garayoa M, San-Segundo L, Hernandez-Iglesias T, de Alava E, Shao W, Yao YM, Pandiella A, et al. In vitro and in vivo rationale for the triple combination of panobinostat (LBH589) and dexamethasone with either bortezomib or lenalidomide in multiple myeloma. Haematologica. 2010; 95: 794-803.

84. Christiansen AJ, West A, Banks KM, Haynes NM, Teng MW, Smyth MJ, Johnstone RW. Eradication of solid tumors using histone deacetylase inhibitors combined with immune-stimulating antibodies. Proc Natl Acad Sci U S A. 2011; 108: 4141-6.

85. Siegel DS, Richardson P, Dimopoulos M, Moreau P, Mitsiades C, Weber D, Houp J, Gause C, Vuocolo S, Eid J, Graef T, Anderson KC. Vorinostat in combination with lenalidomide and dexamethasone in patients with relapsed or refractory multiple myeloma. Blood Cancer J. 2014; 4: e202.

86. Asosingh K, Radl J, Van Riet I, Van Camp B, Vanderkerken $\mathrm{K}$. The 5TMM series: a useful in vivo mouse model of human multiple myeloma. Hematol J. 2000; 1: 351-6.

87. Barlogie B, Pineda-Roman M, van Rhee F, Haessler J, Anaissie E, Hollmig K, Alsayed Y, Waheed S, Petty N, Epstein J, Shaughnessy JD, Jr., Tricot G, Zangari M, et al. Thalidomide arm of Total Therapy 2 improves complete remission duration and survival in myeloma patients with metaphase cytogenetic abnormalities. Blood. 2008; 112: 3115-21.

88. Barlogie B, Tricot G, Anaissie E, Shaughnessy J, Rasmussen E, van Rhee F, Fassas A, Zangari M, Hollmig K, Pineda-Roman M, Lee C, Talamo G, Thertulien R, et al. Thalidomide and hematopoietic-cell transplantation for multiple myeloma. N Engl J Med. 2006; 354: 1021-30.

89. Kassambara A, Hose D, Moreaux J, Walker BA, Protopopov A, Reme T, Pellestor F, Pantesco V, Jauch A, Morgan G, Goldschmidt H, Klein B. Genes with a spike expression are clustered in chromosome (sub)bands and spike (sub)bands have a powerful prognostic value in patients with multiple myeloma. Haematologica. 2012; 97: 622-30.

90. Cui X, Churchill GA. Statistical tests for differential expression in cDNA microarray experiments. Genome Biol. 2003; 4: 210.

91. Le Carrour T, Assou S, Tondeur S, Lhermitte L, Lamb N, Reme T, Pantesco V, Hamamah S, Klein B, De Vos J. Amazonia!: An Online Resource to Google and Visualize Public Human whole Genome Expression Data. The Open Bioinformatics Journal. 2010; 4: 5-10.

92. Reme T, Hose D, De Vos J, Vassal A, Poulain PO, Pantesco V, Goldschmidt H, Klein B. A new method for class prediction based on signed-rank algorithms applied to Affymetrix microarray experiments. BMC Bioinformatics. 2008; 9: 16. 